\begin{tabular}{lc} 
SCIENCE \& TECHNOLOGY \\
Journal homepage: http://www.pertanika.upm.edu.my/ \\
\hline PERTANIKA
\end{tabular}

\title{
Assessing the Impacts of Competition and Dispersal on a Multiple Interactions Type Model
}

\author{
Murtala Bello Aliyu ${ }^{1,2 *}$, Mohd Hafiz Mohd ${ }^{1,3}$ and Mohd Salmi Md. Noorani ${ }^{3}$ \\ ${ }^{1}$ School of Mathematical Sciences, Universiti Sains Malaysia, 11800 USM, Penang, Malaysia \\ ${ }^{2}$ Department of Mathematics, Nigerian Defence Academy, Afaka, PMB 2019, Kaduna, Nigeria \\ ${ }^{3}$ Department of Mathematical Sciences, Faculty of Science and Technology, Universiti Kebangsaan Malaysia, \\ 43600 UKM, Bangi, Selagor, Malaysia
}

\begin{abstract}
Multiple interactions (e.g., mutualist-resource-competitor-exploiter interactions) type models are known to exhibit oscillatory behaviour as a result of their complexity. This large-amplitude oscillation often de-stabilises multispecies communities and increases the chances of species extinction. What mechanisms help species in a complex ecological system to persist? Some studies show that dispersal can stabilise an ecological community and permit multi-species coexistence. However, previous empirical and theoretical studies often focused on one- or two-species systems, and in real life, we have more than two-species coexisting together in nature. Here, we employ a (four-species) multiple interactions type model to investigate how competition interacts with other biotic factors and dispersal to shape multi-species communities. Our results reveal that dispersal has (de-)stabilising effects on the formation of multi-species communities, and this phenomenon shapes coexistence mechanisms of interacting species. These contrasting effects of dispersal can best be illustrated through its combined influences with the competition. To do this, we employ numerical simulation and bifurcation analysis techniques to track the stable and unstable attractors of the system. Results show the presence of Hopf bifurcations, transcritical

ARTICLE INFO

Article history:

Received: 11 October 2020

Accepted: 30 April 2021

Published: 31 July 2021

DOI: https://doi.org/10.47836/pjst.29.3.04

E-mail addresses:

murtalabelloaliyu@gmail.com (Murtala Bello Aliyu)

mohdhafizmohd@usm.my (Mohd Hafiz Mohd)

msn@ukm.edu.my (Mohd Salmi Md. Noorani)

* Corresponding author

bifurcations, period-doubling bifurcations and limit point bifurcations of cycles as we vary the competitive strength in the system. Furthermore, our bifurcation analysis findings show that stable coexistence of multiple species is possible for some threshold values of ecologically-relevant parameters in this complex system. Overall,
\end{abstract}


we discover that the stability and coexistence mechanisms of multiple species depend greatly on the interplay between competition, other biotic components and dispersal in multi-species ecological systems.

Keywords: Hopf bifurcation, limit cycle, limit point bifurcation, period-doubling bifurcation, stability, transcritical bifurcation.

\section{INTRODUCTION}

Competition for the scarce resource is a renowned interaction that often occurs in an ecological system (Gause, 1932). The Lotka-Volterra competition model is a well-known competition model (Grover et al., 1997; Mohd, 2019). The result from this model analysis shows that two or more species can only coexist if and only if the intraspecific competition is greater than interspecific competition (Gotelli, 2008; Mittelbach \& McGill, 2019). In contrast, if the interspecific competition is greater than the intraspecific competition, this scenario leads to the exclusion of species from the system ("principle of competitive exclusion") (Hardin, 1960). However, this situation contrast with real-world phenomena as many species coexist in nature and this observation is being postulated as the "paradox of phytoplankton" (Hutchinson, 1961). This paradox describes the situation in which a limited range of resources supports a great diversity of species. To re-address this problem, we hypothesise that there could be some essential mechanisms like dispersal and different forces of biotic interactions that lead to the coexistence of complex ecological systems (Tubay et al. 2013; Kakishima et al., 2015). Therefore, an important question is, how do we generalise a simple coexistence mechanism inferred by classical ecological theories to multi-species communities? One possible way to do this is through the use of multiple interactions type modelling framework and the incorporation of spatial diffusion mechanism into such a system to model the effects of local dispersal of multiple species.

In general, research on simple ecological communities attempted to integrate different modules of interaction into a multi-species system (Kondoh, 2008) and demonstrated that a mixed type of interaction is more plausible in modelling natural ecosystems. The complex interspecific interactions between multiple species are typical features of ecological ecosystems, and those interactions are in the form of predation, parasitism, competition, and mutualism. Some studies have suggested that ecological communities (Kondoh \& Mougi, 2015; Mougi \& Kondoh, 2012; Mougi \& Kondoh, 2014; Mougi, 2016) have a synergistic effect between interaction type and species diversity. Some simulation studies involving multiple interacting species illustrate complex dynamical behaviours such as oscillations and chaotic dynamics (Shabunin et al., 2005). Another modelling work involving a fourspecies system demonstrates that dispersal plays an important role in shaping the population dynamics of multi-species communities (Kouvaris et al., 2011). It has also been discovered that distinct dispersal mechanisms, coupled with species interactions, can determine the 
occurrence of the different amplitude of oscillations in community structures (Shabunin \& Provata, 2013).

Dispersal in multi-species communities can stabilise population dynamics, reduces local extinction of species and support recolonisation of species (Crowley, 1981; Briggs \& Hoopes, 2004; Lampert \& Hasting, 2016). Dispersal is an essential concept in conservation biology and spatial ecology (Hanski, 1998; Crooks \& Sanjayan, 2006; Kindlmann \& burel, 2008; Kool et al., 2013). Dispersal helps species migrate into a new community and adapt to the changes in such community (Bullock et al., 2002, Aliyu \& Mohd, 2021). Several demographic, evolutionary and ecological processes drive dispersal evolution. For instance kin competition (Gandon \& Rousset, 1999; Bach et al., 2006; Poethke et al., 2007), inbreeding avoidance (Gandon, 1999; Perrin \& Goudet, 2001), density-dependent factor (Poethke \& Hovestadt, 2002; Hovestadt et al., 2010), spatio-temporal habitat variability (Travis, 2001; Poethke et al., 2003) have been reported to affect dispersal positively by their synchronising effects. Synchronising effect is a term used to describe the interactions that exist between extrinsic environmental variation and population dynamics. Several empirical and theoretical studies have illustrated how antagonistic interactions and environmental factors shape the evolution of species dispersal (Mondor et al., 2005; Green, 2009; Poethke et al., 2010; Chaianunporn \& Hovestadt, 2015; Amarasekare, 2016). Strong oscillation is a direct consequence of antagonistic interactions in multi-species communities, and this has led to spatio-temporal variation in the species fitness (Green, 2009; Chaianunporn \&Hovestadt, 2012). Weak dispersal strength has a synchronisation effect on large amplitude population cycles across space; a phenomenon called phase-locking (Bjørnstad, 2000; Vasseur \& Fox, 2009; Vogwill et al., 2009). There is little possibility for dispersal-induced stabilisation when the population cycles in the system undergo spatial synchronisation (Yaari et al., 2012).

Numerous empirical and theoretical studies have reported how dispersal effects reduce species population variability and subsequently, extinction rate (Vogwill et al., 2009; Abbott, 2011). However, there are divergent views on the impact of dispersal on the stability of the multi-species community. Increase in spatial synchrony (i.e. variation in time-dependent characteristics or abundance of different geographical populations) is a product of stabilising effects of dispersal on a local population (Kendall et al., 2000). In some other studies, these synchronisation effects distort species stability and persistence (Feyrer et al., 2015; Gouhier et al., 2010). Thus, Hudson and Cattadori (1999) describe dispersal as a sword with double-edge: dispersal can reduce species variability through its stabilising effects or increase them through synchronisation effects. Some experimental studies report that dispersal effects could either be destabilising, stabilising or no effects on multi-species communities (Dey \& Joshi, 2006; Steiner et al., 2013; Mohd et al., 2017). Given these controversies, it becomes imperative to assess the impacts of competition and 
dispersal on multi-species coexistence. Specifically, it remains unexplored the effects of competition and dispersal on multiple interactions type model.

To address this problem, we extend the ecological model by adding the diffusion term; this incorporation leads to a system of partial differential equations (PDE) (Mitani \& Mougi, 2017). We investigate numerically how competition and dispersal shape multi-species structures, stability and their coexistence mechanisms. From the numerical simulation results, we identify several observations as a result of the interplay between competition and dispersal in this multiple interactions type system. Finally, we discuss the ecological implications of our findings for the conservation of the natural ecosystem.

\section{MATERIAL AND METHODS}

\section{Model Description and Theoretical Analysis}

We propose a system of PDE for the densities $X(x, t), W(x, t), Y(x, t)$ and $Z(x, t)$ in onedimension $(0 \leq \mathrm{x} \leq 1)$ (Equation 1) (Mitani \& Mougi, 2017; Mohd et al., 2017):

$$
\begin{aligned}
& \frac{\partial X}{\partial t}=X\left(r_{k}-\mathrm{X}-\beta \mathrm{W}-a \mathrm{Y}+\frac{u Z}{h_{Z}+Z}\right)+D_{X} \frac{\partial^{2} X}{\partial x^{2}} \\
& \frac{\partial W}{\partial t}=W\left(r_{W}-\mathrm{W}-\alpha \mathrm{X}\right)+D_{W} \frac{\partial^{2} W}{\partial x^{2}} \\
& \frac{\partial Y}{\partial t}=Y(g a X-d)+D_{Y} \frac{\partial^{2} Y}{\partial x^{2}} \\
& \frac{\partial Z}{\partial t}=Z\left(r_{Z}-\mathrm{Z}+\frac{v X}{h_{X}+X}\right)+D_{Z} \frac{\partial^{2} Z}{\partial x^{2}}
\end{aligned}
$$

where $X, W, Y, Z$ represent the population densities of resource, competitor, exploiter, and mutualist species, respectively. The parameter $r_{k}$ is the rate at which the resource species grows; $r_{w}$ is the rate at which the competitor species grows; $r_{z}$ is the rate at which the mutualist species grows; $\alpha$ and $\beta$ represent the strength of competition (i.e., resource and competitor species, respectively); $a$ represents capture rate (i.e., the rate at which the exploiter species capture the prey). The term $g$ represents the conversion efficiency; $d$ represents exploiter species death; $u$ and $v$ represent the benefits from the mutualistic interactions (i.e., mutualistic strength of the resource and mutualist species, respectively); $h_{X}$ and $h_{Z}$ represent the half-saturation constant of resource and mutualist species, respectively (i.e., density at which half the average intake of prey is achieved, irrespective of the prey population available). It is assumed that the self-regulation mechanism of mutualist species (net effect of a mutualist on the other mutualist species) is unity for theoretical simplicity. Equation (1) is a spatial extension of the multiple interactions type 
model (Mitani \& Mougi, 2017). In the absence of dispersal $\left(D_{x}=D_{w}=D_{y}=D_{z}=0\right)$, the ecological system becomes a system of ordinary differential equations (ODE). The steady states of the ODE system can be computed analytically by letting the time-derivative equal zero which gives:

1. Extinction equilibrium: $E_{0}(0,0,0,0)$,

2. Extinction of resource species equilibrium: $E_{1}\left(0, r_{W}, \frac{1}{a}\left(-\beta W^{*}+\left(\frac{u Z^{*}}{h_{Z}+Z^{*}}\right)\right), r_{Z}\right)$,

3. Extinction of competitor species equilibrium: $E_{2}\left(\frac{d}{g a}, 0, \frac{1}{a}\left(r_{k}-X^{*}+\left(\frac{u Z^{*}}{h_{Z}+Z^{*}}\right)\right), r_{Z}+\left(\frac{v X^{*}}{h_{X}+X^{*}}\right)\right)$,

4. Extinction of exploiter species equilibrium: $E_{3}\left(\frac{d}{g a}, r_{W}-\alpha X^{*}, 0, r_{Z}+\left(\frac{v X^{*}}{h_{X}+X^{*}}\right)\right)$,

5. Extinction of mutualist species equilibrium: $E_{4}\left(\frac{d}{g a}, r_{W}-\alpha X^{*}, \frac{1}{a}\left(r_{k}-X^{*}-\beta W^{*}\right), 0\right)$,

6. Four-species coexistence equilibrium: $E_{5}\left(\frac{d}{g a}, r_{W}-\alpha X^{*}, \frac{1}{a}\left(r_{k}-\frac{d}{g a}-r_{W} \beta-\frac{d \alpha \beta}{g a,}+\frac{u M^{*}}{Q^{*}}\right), \frac{r_{Z}+v d}{Q^{*}}\right)$.

where $M^{*}=r_{Z}(g a h X+d)+v d$ and $Q^{*}=g a h X+d$.

We can analyse the stability of each steady state by using Jacobian matrix to calculate their respective eigenvalues, which is given by:

$$
J=\left[\begin{array}{cccc}
r_{k}-2 X^{*}-\beta W^{*}-a Y^{*}+\frac{u Z^{*}}{h_{Z}+Z^{*}} & -\beta X^{*} & -a Y^{*} & X^{*}\left(\frac{u}{h_{Z}+Z^{*}}-\frac{u Z^{*}}{\left(h_{Z}+Z^{*}\right)^{2}}\right) \\
-\alpha W^{*} & r_{W}-2 W^{*}-\alpha X^{*} & 0 & 0 \\
g a Y^{*} & 0 & g a X^{*}-d & 0 \\
Z^{*}\left(\frac{v}{h_{X}+X^{*}}-\frac{v X^{*}}{\left(h_{X}+X^{*}\right)^{2}}\right) & 0 & 0 & r_{Z}-2 Z^{*}+\frac{v X^{*}}{h_{X}+X^{*}}
\end{array}\right]
$$

We note that if all the real parts of the eigenvalues are negative, it follows that the steady state is stable. For example, the extinction equilibrium $E_{0}(0,0,0,0)$ has the following eigenvalues: $\lambda_{1}=r_{K}, \lambda_{2}=r_{W}, \lambda_{3}=-\mathrm{d}$, and $\lambda_{4}=r_{Z}$. Since some eigenvalues are positive and $\lambda_{3}$ is negative, it follows that $E_{0}(0,0,0,0)$ is unstable equilibrium (i.e., saddle type). The eigenvalues of the remaining steady states can be calculated using same techniques.

When the effect of local dispersal is considered $\left(D_{X}=D_{W}=D_{Y}=D_{Z}>0\right)$ and the diffusion term is added into the system, the model (1) now becomes a system of PDE, which is a spatial extension of the multiple interactions type model (Mitani \& Mougi, 2017). The term $D_{i}(i=\mathrm{X}, W, Y, Z)$ represents the dispersal strength along spatial domain $(x)$. We assume equal dispersal strength for all the interacting species $\left(D_{X}=D_{W}=D_{Y}=D_{Z}=\right.$ $0.005)$. Also, we apply zero-flux boundary conditions for each of the interacting species (Equation 2) (i.e., no movement is allowed across the boundaries):

$$
D_{X} \frac{\partial X(0, t)}{\partial x}=D_{X} \frac{\partial X(1, t)}{\partial x}
$$




$$
\begin{aligned}
& D_{W} \frac{\partial W(0, t)}{\partial x}=D_{W} \frac{\partial W(1, t)}{\partial x} \\
& D_{Y} \frac{\partial Y(0, t)}{\partial x}=D_{Y} \frac{\partial Y(1, t)}{\partial x} \\
& D_{Z} \frac{\partial Z(0, t)}{\partial x}=D_{Z} \frac{\partial Z(1, t)}{\partial x}
\end{aligned}
$$

To solve Equation 1 with the boundary conditions as in Equations 2, we use the method of line. This numerical approach is implemented in XPPAUT, which provides a good platform for solving PDE systems in one spatial variable $x$ (Mohd, 2019). The spatial domain is divided into meshes of $M+1$ equivalent points of $x_{i}=i h$ for $i=0,1, \ldots, M(0$ $\leq x \leq 1)$. The central difference approximation is then employed to replace the spatial derivative in model (1). In this numerical method, the zero-flux boundary conditions are encoded into the scheme using finite difference approximation. The resulting transformation results in a $4(N+1)$ ODE scheme, one for each species at spatial location $x_{i}$. The regular ODE solver, cvode, is used for solving the resulting ODE system for $t=1000$ (i.e., until steady-state). The size of the mesh used in the numerical simulation is $h=0.09$. We have also used AUTO to continue the steady-state, in which case we tracked the stable, unstable and bifurcation points that arise as the parameters change in this ecological system (Omaiye $\&$ Mohd, 2018). It is also verified that the numerical results are insensitive to changes in grid spacing (i.e., by increasing and decreasing the number of finite difference points). Since the PDE model (1) is nonlinear, we conducted local stability analysis whereby the system is linearised about the steady states via numerical techniques. To do this, the Jacobian matrix and the spectrum of eigenvalues are calculated numerically using fsolve and eig functions in MATLAB. Note that the steady state is stable if all the real parts of the eigenvalues are negative (and otherwise unstable). Further discussion on this topic (i.e., numerical stability analysis of PDE system) can be found in the modelling work of Mohd (2018). The parameter values used in the numerical simulation are defined in Table 1, which are motivated by the ecological studies of (Mitani \& Mougi, 2017; Mohd et al., 2017; Mohd et al., 2018).

\section{RESULT}

The effects of dispersal on this multiple interactions type system is illustrated in Figures 1-4. We observe that dispersal influence the coexistence mechanisms of this multi-species ecological system. The interacting species disperse from areas of high competition to low competition to avoid going extinct due to the complexity of interactions in the community. In the later section, it is observed that steady state phenomena and oscillatory dynamics 
Table 1

Symbols, their definitions and the parameter values used for the numerical simulations

\begin{tabular}{clc}
\hline Symbol & Definition & Parameter value \\
\hline$r_{k}$ & The intrinsic growth rate of resource species & 1 \\
$r_{w}$ & The intrinsic growth rate of competitor species & 1 \\
$r z$ & The intrinsic growth rate of the mutualist species & 1 \\
$u$ & Maximum benefit of the mutualistic interaction & 3 \\
$v$ & Maximum benefit of the mutualistic interaction & 2 \\
$a$ & Capture rate & 1.8 \\
$g$ & Conversion efficiency of the exploiter species & 0.25 \\
$d$ & Death rate of the exploiter & 0.05 \\
$h_{x}$ & Half saturation constant of the hyperbolic functional response & 1 \\
$h_{z}$ & Half saturation constant of the hyperbolic functional response & 1 \\
$\beta$ & Competitive strength of the competitor species & 0.7 \\
$a$ & Competitive strength of the resource species & 0.2 \\
$D_{X}=D_{W}=D_{Y}=D_{Z}$ & Dispersal strength & 0.005 \\
\hline
\end{tabular}

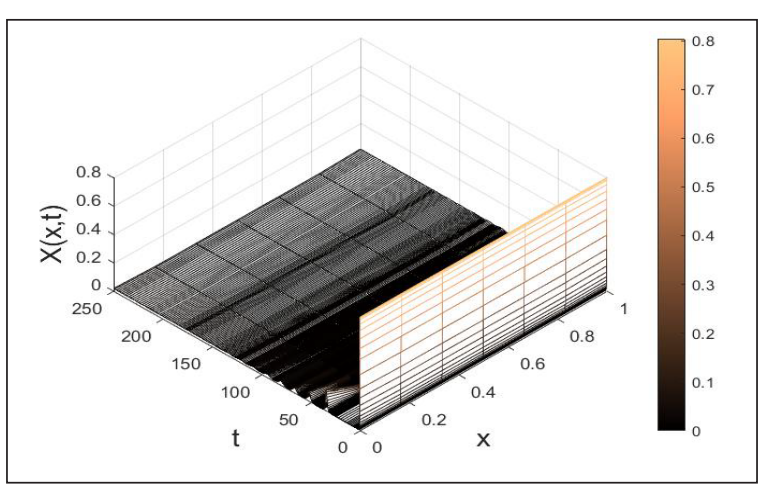

Figure 1. The effects of dispersal on the resource species using model (1) with $D_{X}=D_{W}=D_{Y}=D_{Z}=0.005$. Initial species density $\mathrm{X}(\mathrm{x}, \mathrm{t}=0)=0.9, \mathrm{~W}(\mathrm{x}, \mathrm{t}=0)=0.3, \mathrm{Y}(\mathrm{x}, \mathrm{t}=0)=0.2, \mathrm{Z}(\mathrm{x}, \mathrm{t}=0)=0.8$. The diagram is plotted using MATLAB ode15s solver and the parameter values as in Table 1.

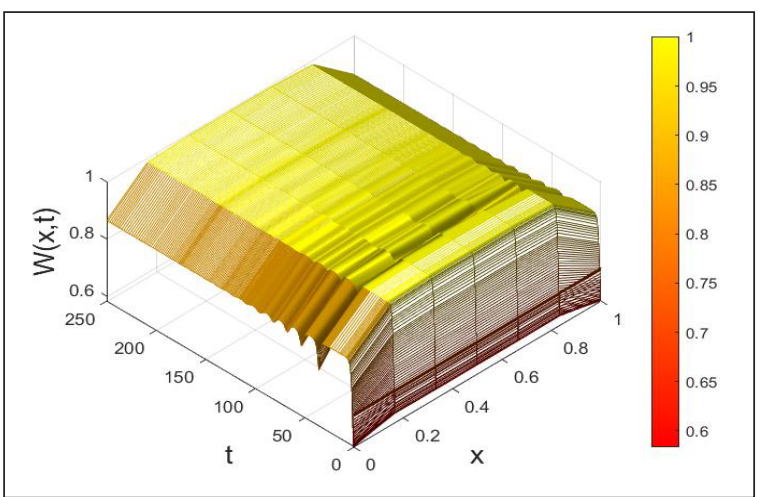

Figure 2. The effects of dispersal on the competitor species using model (1) with $D_{X}=D_{W}=D_{Y}=D_{Z}=$ 0.005 . Initial species density $\mathrm{X}(\mathrm{x}, \mathrm{t}=0)=0.9, \mathrm{~W}(\mathrm{x}, \mathrm{t}=0)=0.3, \mathrm{Y}(\mathrm{x}, \mathrm{t}=0)=0.2, \mathrm{Z}(\mathrm{x}, \mathrm{t}=0)=0.8$. The diagram is plotted using MATLAB ode15s solver and the parameter values as in Table 1. 


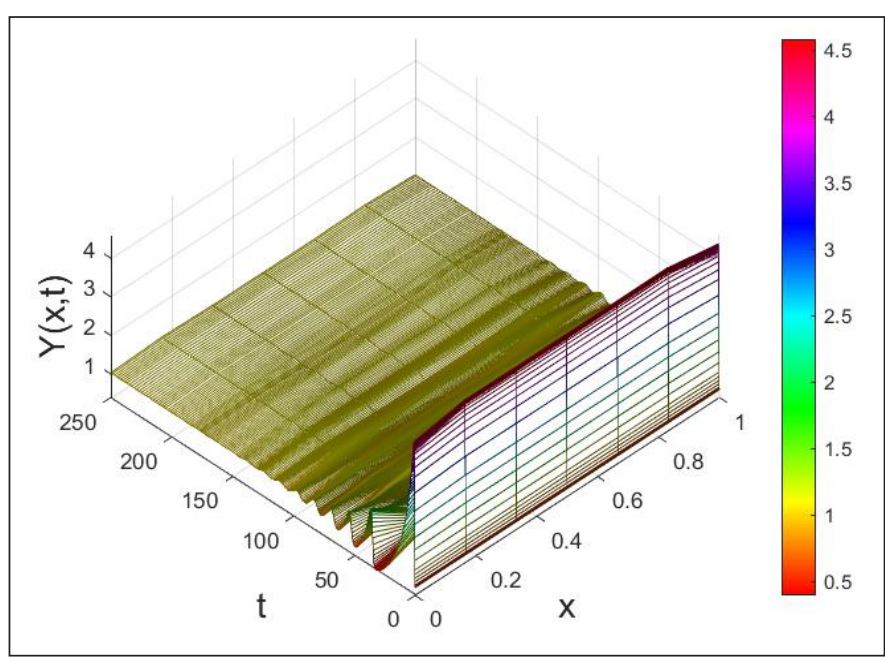

Figure 3. The effects of dispersal on the exploiter species using model (1) with $D_{X}=D_{W}=D_{Y}=D_{Z}=0.005$. Initial species density $\mathrm{X}(\mathrm{x}, \mathrm{t}=0)=0.9, \mathrm{~W}(\mathrm{x}, \mathrm{t}=0)=0.3, \mathrm{Y}(\mathrm{x}, \mathrm{t}=0)=0.2, \mathrm{Z}(\mathrm{x}, \mathrm{t}=0)=0.8$. The diagram is plotted using MATLAB ode15s solver and the parameter values as in Table 1.

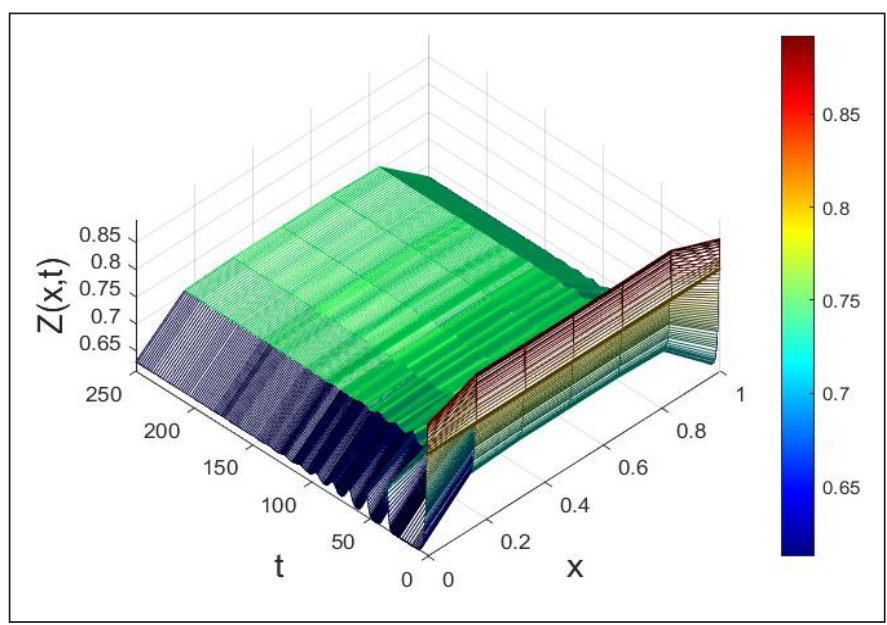

Figure 4. The effects of dispersal on the mutualist species using model (1) with $D_{X}=D_{W}=D_{Y}=D_{Z}=0.005$. Initial species density $\mathrm{X}(\mathrm{x}, \mathrm{t}=0)=0.9, \mathrm{~W}(\mathrm{x}, \mathrm{t}=0)=0.3, \mathrm{Y}(\mathrm{x}, \mathrm{t}=0)=0.2, \mathrm{Z}(\mathrm{x}, \mathrm{t}=0)=0.8$. The diagram is plotted using MATLAB ode15s solver and the parameter values as in Table 1.

are the plausible behaviour of this multi-species system with dispersal. This findings are parallel to some theoretical studies which report that dispersal strength influences species coexistence outcomes (i.e., steady state or population oscillation) (Goldwyn \& Hastings, 2008; Williams \& Hastings, 2013; Anderson \& Hayes, 2018; Bassett et al., 2017; Chow et al., 2018). To have a good understanding of how species competitive strength affects the community stability and species coexistence mechanisms, we conduct co-dimension one bifurcation analysis using $\beta$ and $\alpha$ as our bifurcation parameters in the following sections. 


\section{The Dynamics of the Ode Model in the Absence of Dispersal $(D=0)$}

Since our goal is to better understand how competitive interactions shape community dynamics in multiple interactions type model, we perform co-dimension one bifurcation analysis using parameter $\beta$, i.e., the strength of competitor species. Bifurcation analysis provide a good techniques for studying different dynamics of nonlinear PDE (Mohd, 2018). As an example, Figure 5 illustrates the population density of prey species $(X)$ as parameter $\beta$ is changed with other parameter values are given in Table 1 . There occur several critical values in this co-dimension one bifurcation diagram corresponding to supercritical Hopf bifurcation (i.e., $H B$ ) and transcritical bifurcations (i.e., $B P 1$ and $B P 2)$. We notice the existence of some branches of steady states, particularly unstable (black curves) and stable (red curves) steady states. As the competitive strength $\beta$ increases, the emergence of distinct outcomes of species interactions are observed: (i) four-species steady-state (i.e., when $\beta<H B$ ); (ii) bistable outcomes between three- and two-species steady states (i.e., when $B P 2<\beta<B P 1$ ); (iii) two-species steady states (i.e., when $\beta>B P 1$ ). When $H B<\beta<B P 2$, oscillatory behaviour (green dots) emerges with population fluctuations in this four-species system are observed; in this case, stable limit

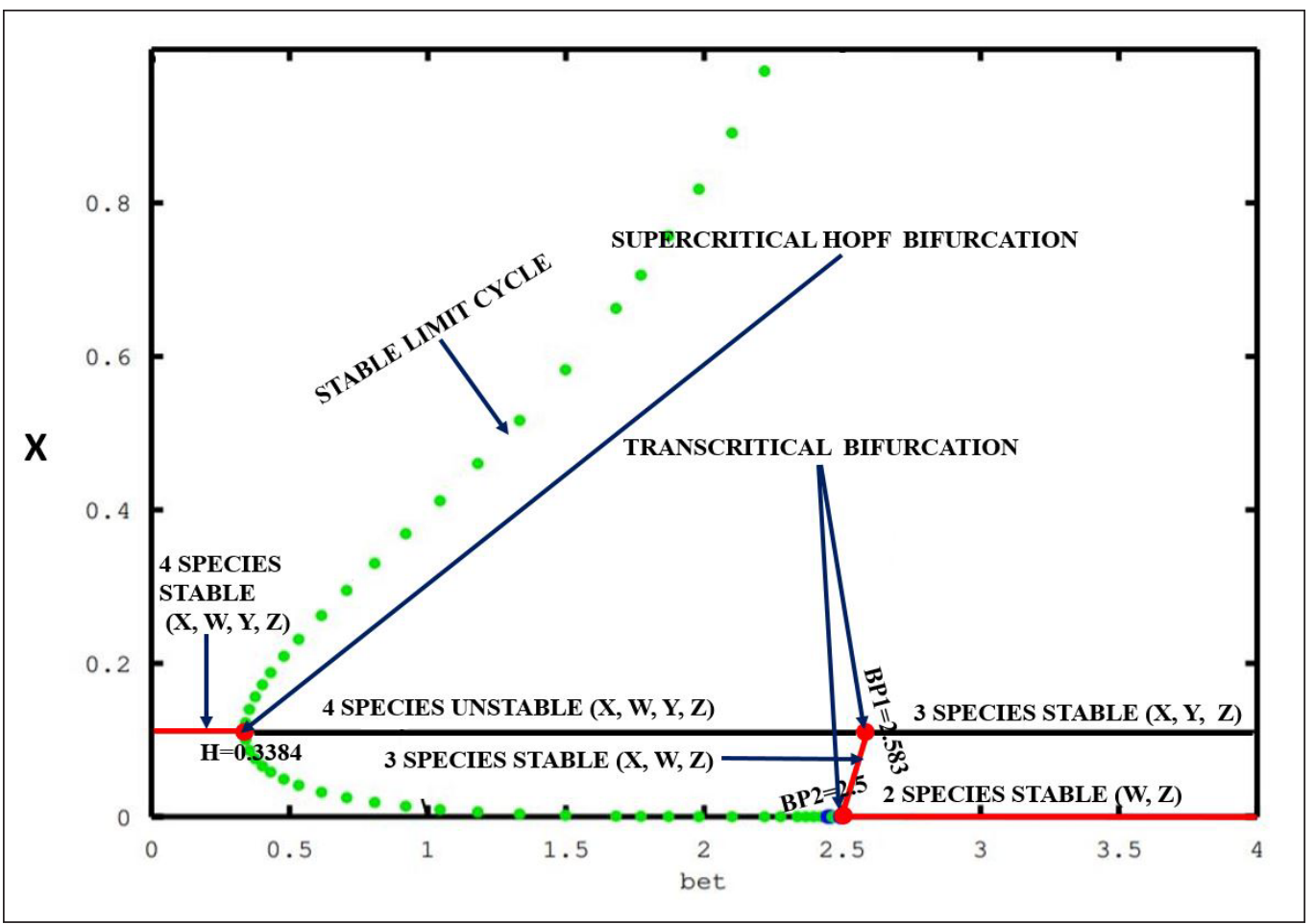

Figure 5. Co-dimension one bifurcation analysis as the density of species $\mathrm{X}$ varies against $\beta$ in the model (1) without dispersal $(\mathrm{D}=0)$. This bifurcation diagram shows different dynamics that occur in the ODE system. Initial population densities: $X(x ; t=0)=0: 9, W(x ; t=0)=0: 7, Y(x ; t=0)=0: 6, Z(x ; t=0)=0: 8$. The diagram is plotted using XPPAUT package and the parameter values as in Table 1 


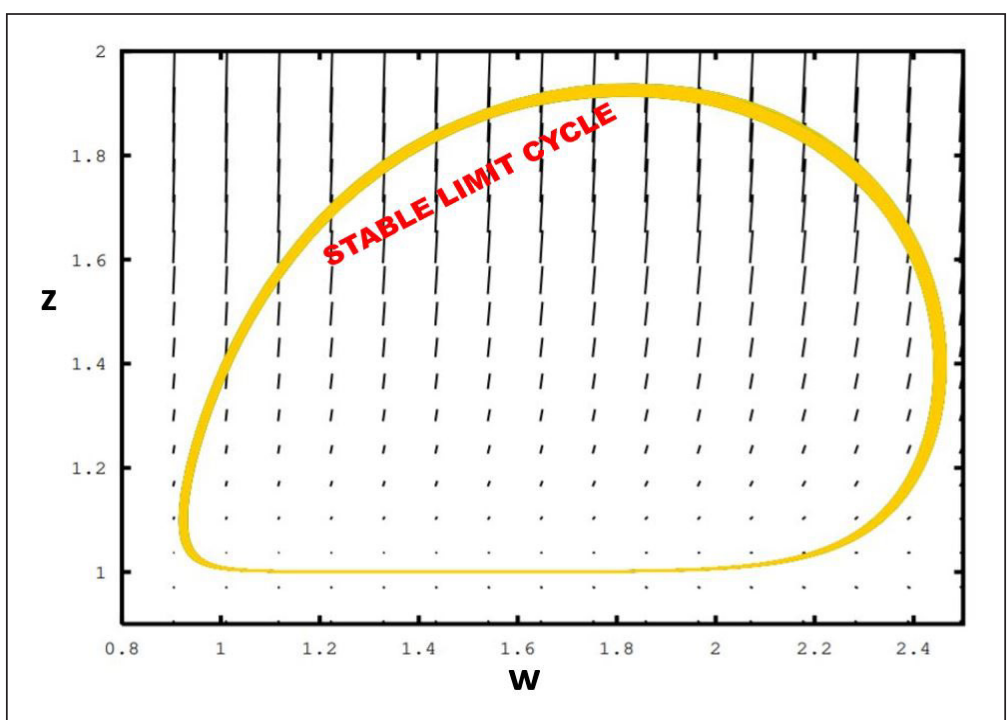

Figure 6. Stable limit cycle of model (1) with $\mathrm{D}=0$. Initial species density $\mathrm{X}(\mathrm{x}, \mathrm{t}=0)=0.9, \mathrm{~W}(\mathrm{x}, \mathrm{t}=0)=0.3$, $\mathrm{Y}(\mathrm{x}, \mathrm{t}=0)=0.2, \mathrm{Z}(\mathrm{x}, \mathrm{t}=0)=0.8$. The diagram is plotted using XPPAUT and the parameter values as in Table 1.

cycles (Figure 6) appear with all steady states of the system become unstable. Due to this reason, the trajectories do not converge to any steady-state as it converges to a stable limit cycle from positive initial densities. Based on these observations, we realise that Hopf bifurcation is the best-known mechanism that mediates oscillatory dynamics in this ecological system. These bifurcation changes in dynamics and their consequences on species coexistence outcomes has been observed in several other studies (Liu \& Huang, 2018; Gyllenberg et al., 2019; Mohd, 2019; Wei et al. 2020).

\section{Joint Effects of Competition and Dispersal in the Multiple Interactions Type PDE Model}

To explain the differences observed in the number of species that persist as shown by Figure 7, we perform co-dimension one bifurcation analysis of the PDE model (1) and the result is depicted in Figure 7. This bifurcation diagram shows the density of resource species $(X)$ as $\beta$ varies. There occurs several threshold values of $\beta$, which correspond to transcritical bifurcation points (i.e., $B P 1, B P 2$ and $B P 3$ ). As we cross these critical points, different presence-absence of species are seen: (i) four-species coexistence (i.e., when $\beta<B P 3$ ); (ii) three-species coexistence with species $Y$ absent (i.e., when $B P 3<\beta<B P 2$ ); (iii) two-species coexistence with species $X$ and $Y$ absent (i.e., when $B P 2<\beta<B P 1$ ); (iv) single-species steady-state with only species $Z$ present (i.e., when $\beta>B P 1$ ). We realise that transcritical bifurcation plays an important factor in determining survival (and exclusion) of different interacting species in this multi-species PDE system. It is also discovered that the strength of multiple interactions type arising from distinct ecological populations such as resource, 


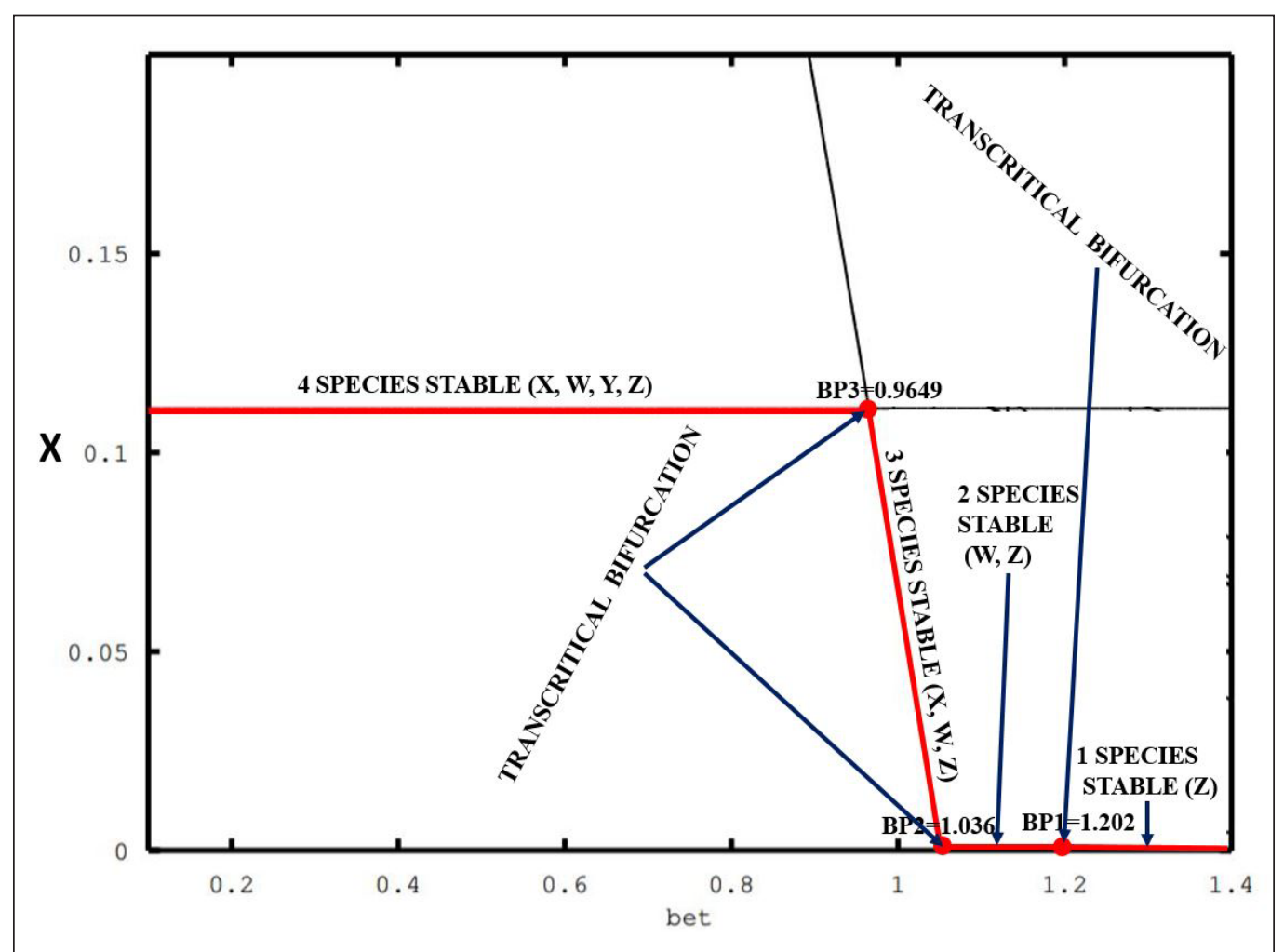

Figure 7. Co-dimension one bifurcation analysis as the density of species $\mathrm{X}$ varies against $\beta$ in the model (1) with dispersal $\left(D_{X}=D_{W}=D_{Y}=D_{Z}=0.005\right)$. This bifurcation diagram shows different dynamics that occur in the ODE system. Initial population densities: $X(x ; t=0)=0: 9, \mathrm{~W}(\mathrm{x} ; \mathrm{t}=0)=0: 7, \mathrm{Y}(\mathrm{x} ; \mathrm{t}=0)=$ $0: 6, \mathrm{Z}(\mathrm{x} ; \mathrm{t}=0)=0: 8$. The diagram is plotted using XPPAUT package and the parameter values as in Table 1

competitor and exploiter species is amplified in the presence of dispersal, which can weaken the chance of species survival in the system.

Closer examination of our bifurcation analysis results without dispersal (Figure 5) and with dispersal (Figure 7) illustrates some intriguing observations. We found that the inclusion of dispersal into this ecological system promotes more outcomes with four-species coexistence steady state. Without dispersal, we observe that oscillatory dynamics are more pronounced in this multiple interactions type model with species populations oscillate between some maximum and minimum densities. However, one of the concerns with this kind of oscillatory dynamics is that some populations of species would fluctuate to a very low abundance; in the presence of external factors (e.g., stochasticity), this situation would increase the likelihood of extinction and could result in de-stabilisation of multi-species communities (Mohd, 2019). This vulnerability is softened by incorporation of dispersal into the model: multi-species coexistence outcomes are more likely to occur due to the positive effects of dispersal in rescuing some weaker species from going extinct. This observation is consistent with the reports in some theoretical studies that dispersal can 
induce stability and synchrony in complex systems (Fussell et al., 2019; Verma \& Gupta, 2020; Mohd \& Noorani, 2020).

We also investigate the impacts of competition exerted by the resource species, $\alpha$, on this multi-species ecosystem. Figure 8 shows the food web dynamics with respect to the density of resource species $(X)$ as $\alpha$ is varied in the case of no-dispersal $(D=0)$. In general, this ecological system exhibits rich bifurcation structures that are of ecological importance. There occurs numerous threshold values of $\alpha$, which determine different outcomes of the model; in particular, two supercritical Hopf bifurcations ( $H 1$ and $H 2)$, transcritical bifurcation $(B P)$, period-doubling bifurcations $(P D 1, P D 2$ and $P D 3)$ and limit point bifurcations of cycles ( $L P C 1$ to $L P C 10$ ). It is observed that multi-species coexistence is possible as $\alpha<H 1$ or $H 2<$ $\alpha<B P$. When the competitive strength of the resource species is intense $(\alpha>B P)$, exclusion of species occurs with the weaker competing species $(W)$ is being displaced in the long run due to competitive asymmetry. In the case of moderate competitive strength (i.e., in between $H 1$ and $H 2$ ), we realise some stimulating complex dynamics in this multiple interactions type system: stable (green dots) and unstable (blue dots) limit cycles and period-doublings. We

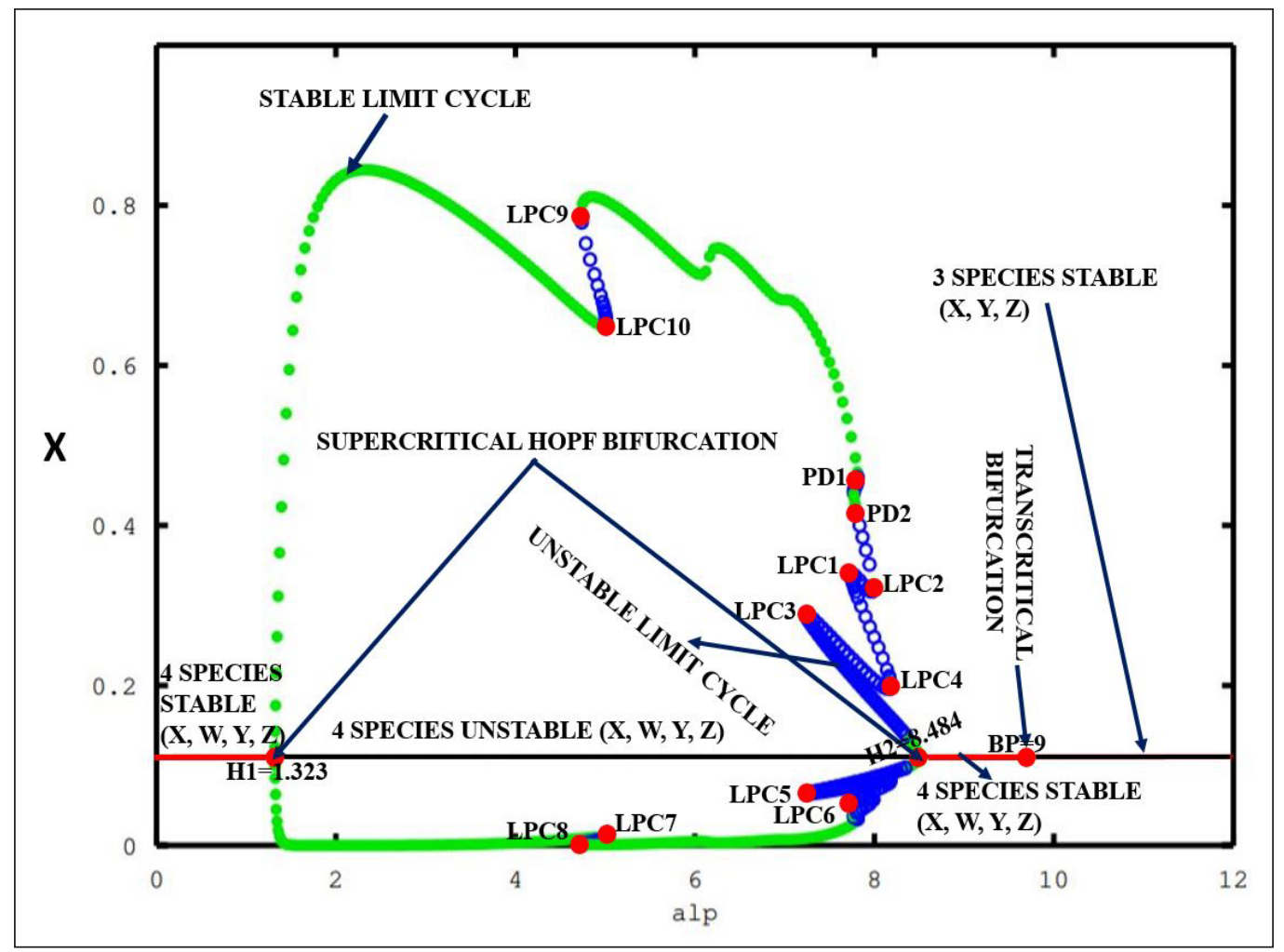

Figure 8. Co-dimension one bifurcation analysis as the density of species $\mathrm{X}$ varies against $\alpha$ in the model (1) without dispersal $(\mathrm{D}=0)$. This bifurcation diagram shows different dynamics that occur in the PDE system. Initial population densities: $\mathrm{X}(\mathrm{x} ; \mathrm{t}=0)=0: 9, \mathrm{~W}(\mathrm{x} ; \mathrm{t}=0)=0: 7, \mathrm{Y}(\mathrm{x} ; \mathrm{t}=0)=0: 6, \mathrm{Z}(\mathrm{x} ; \mathrm{t}=0)=$ $0: 8$. The diagram is plotted using XPPAUT package and the parameter values as in Table 1. 
observe that the stable limit cycles give birth to unstable limit cycles and period-doubling bifurcations and, in some cases, this situation could trigger more complex dynamics. The complex dynamics associated with period-doubling has been observed in some theoretical studies (Selvam \& Dhineshbabu, 2020; Bashkirtseva et al., 2019; Gupta \& Yadav, 2020; Namba et al., 2018; Baek, 2018).

In the presence of dispersal, the system exhibit qualitatively similar bifurcation structures (Figure 9) to no-dispersal scenario (Figure 8), as $\alpha$ is varied. This bifurcation diagram shows that starting from low (or high) $\alpha$ values do not result in sustained oscillation patterns but only lead to attraction towards four- or three-species coexistence steady state. Stable limit cycles of different amplitudes occur from supercritical Hopf bifurcation points ( $H 1$ and $H 2$ ) as the value of $\alpha$ changes to moderate competitive strength. There occurs several period-doubling bifurcations ( $P D 1, P D 2$ and $P D 3)$ and limit point bifurcations of cycles ( $L P C 1$ to LPC6), which can engender complex dynamical behaviour in this ecological system such as aperiodic oscillations (Figure 10). It is also noted that when $\alpha$ $>B P$, competing species $(W)$ is being displaced and thus only three-species coexistence outcome is possible in this situation.

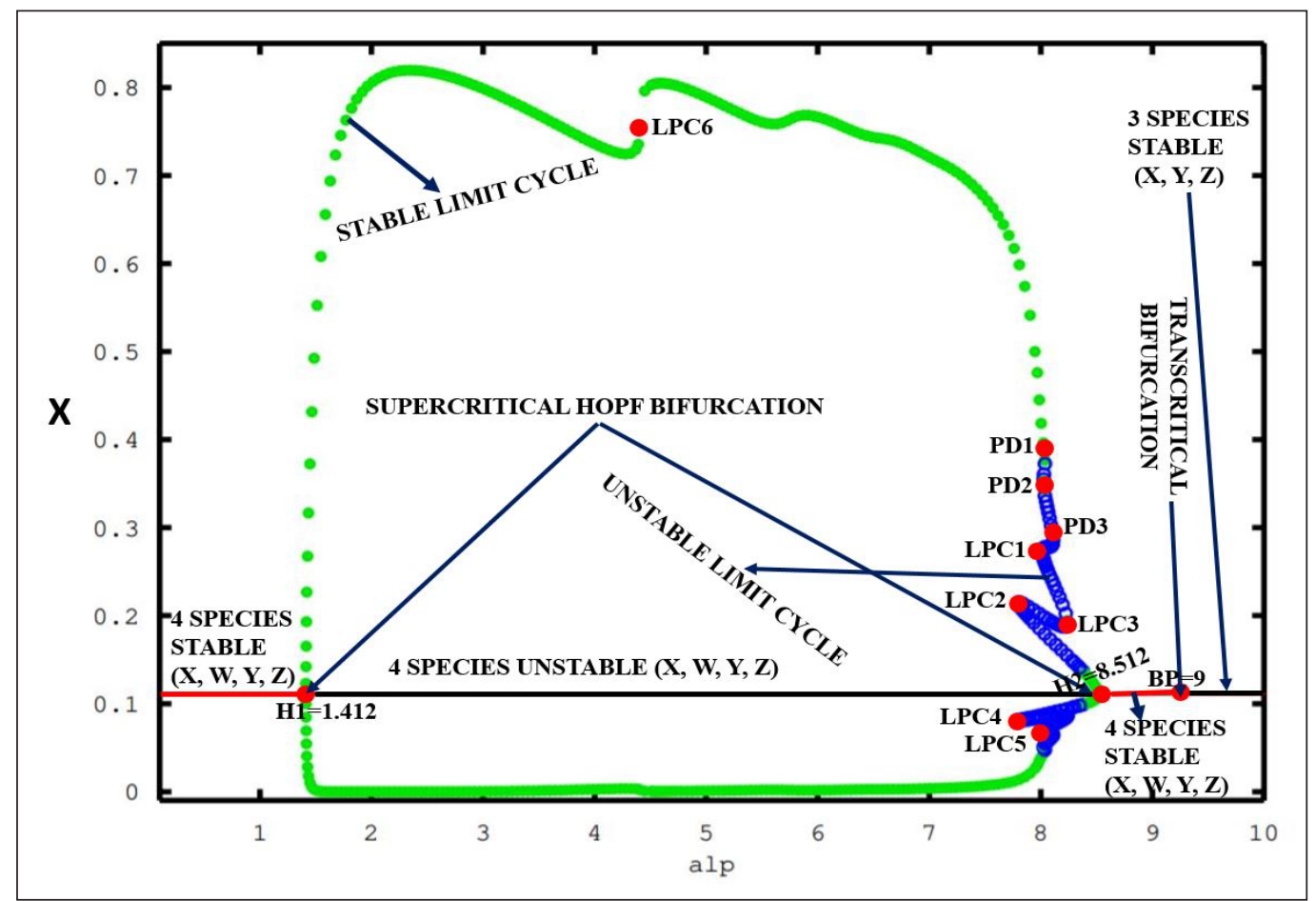

Figure 9. Co-dimension one bifurcation analysis as the density of species $\mathrm{X}$ varies against $\alpha$ in the model (1) with the inclusion of dispersal $\left(D_{X}=D_{W}=D_{Y}=D_{Z}=0.005\right)$. This bifurcation diagram shows different dynamics that occur in the PDE system. Initial population densities: $X(x ; t=0)=0: 9, W(x ; t=0)=0: 7, Y$ $(\mathrm{x} ; \mathrm{t}=0)=0: 6, \mathrm{Z}(\mathrm{x} ; \mathrm{t}=0)=0: 8$. The diagram is plotted using XPPAUT package and the parameter values as in Table 1. 


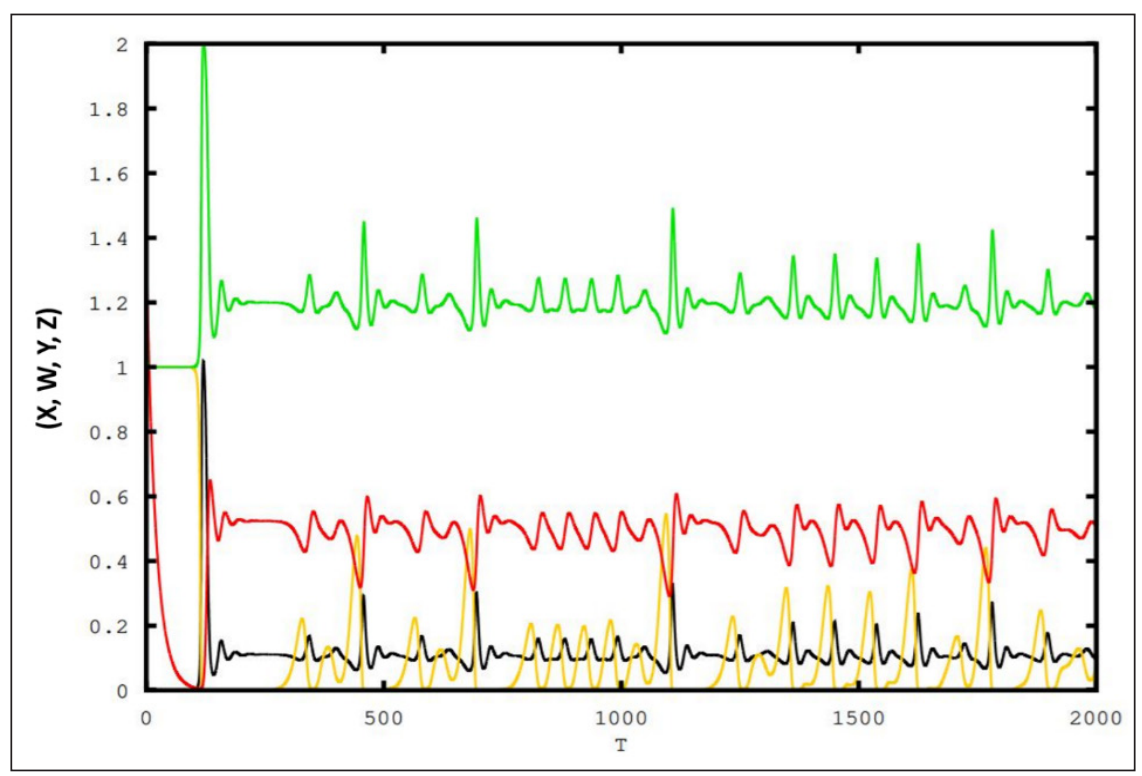

Figure 10. Time series for model (1) in the presence of dispersal $\left(D_{X}=D_{W}=D_{Y}=D_{Z}=0.005\right)$ with $\alpha=$ $8: 1$. Initial population densities: $X(x ; t=0)=0: 9, W(x ; t=0)=0: 7, Y(x ; t=0)=0: 6, Z(x ; t=0)=0: 8$. $\mathrm{X}$ (yellow), W (black), Y (red) and Z (green). The results remains the same for different choices of initial conditions. The diagram is plotted using XPPAUT package and the parameter values in Table 1.

\section{DISCUSSION}

The ecological theories have emphasised the crucial impacts of competition and dispersal in shaping the dynamics of the multi-species system. Thus, a better understanding of their joint effects on the multi-species community assemblies is an important aspect in devising effective species conservation strategies and in maintaining the biodiversity of species. To address these issues, we extended previous multiple interactions type studies (Mitani $\&$ Mougi, 2017) by incorporating a spatial dispersal (i.e., diffusion) term into the system to examine the combined influences of distinct biotic factors and dispersal on community dynamics. In the presence of mutualist-resource-exploiter interactions, our numerical results show that competition and dispersal affect the stability and coexistence of species in the community. The interplay of dispersal with competition shows some intriguing dynamics that are essential for the formation of multi-species ecosystems. An interesting observation from our findings is that the combined influences between competition and dispersal result in different species composition (presence-absence) in this ecological community. Further comparing our results with and without dispersal in this modelling framework shows that there is a qualitative change in the overall dynamics of the ecological system as a result of dispersal and different biotic interactions between multiple species. This finding is in parallel with previous ecological studies (Mohd et al., 2016; Lee et al., 2020), which demonstrated that dispersal has different effects on the outcomes of species interactions. 
Our results in this work extend the insights of some experimental studies (Holyoak, 2000), which used small-scale mesocosm techniques to verify the effects of the paradox of enrichment and dispersal on the persistence of prey-predator species. We discover that large population oscillations are also possible in a multiple interaction type system with dispersal. Our analysis shows the presence of stable and unstable limit cycles (through Hopf bifurcations) together with the emergence of period-doubling bifurcations as the plausible mechanisms that can induce fluctuating populations. These population cycles occur as a result of the interactions between competition and other biotic factors (e.g., mutualistresource-exploiter interactions) in both systems with and without dispersal. This point of view re-enforces some theoretical results that other mechanisms might cause population cycles outside the conventional paradox of enrichment (Turchin, 2003; Rozhnova et al., 2013; Barraquand et al., 2017). The findings in this work demonstrate that the interplay of multiple interactions type and dispersal mediate population cycles as a result of their complexity.

In general, understanding the stability and coexistence mechanisms in multi-species ecosystems is a challenging task, and this issue has been studied from different contexts previously: for instance, regarding the influences of ecological and temporal process (Chesson, 2018; Leibold \& Chase, 2017), the impacts of several limiting resources (Barabás et al., 2018) and the effects of multiple interactions type on multi-species community dynamics (Loreau, 2010; Carrara et al., 2015). Our work adds further insights to these previous studies, and we show that it is possible to maintain species diversity and multi-species coexistence in the presence of dispersal and mutualist-resource-competitorexploiter interactions as long as the interspecific interactions strength is within certain threshold values. This line of thought also agrees with previous studies (Allesina \& Tang, 2012; Becks et al., 2012; Mougi, 2012; Fussman \& Gonzalez, 2013; Koch et al., 2014; Vellend, 2020). Our numerical simulation results have also demonstrated the importance of interaction strength in the overall stability of a multi-species ecological system. These findings further suggest that weak competition strength is a pre-requisite for species stability, coexistence and persistence. This result has shed some light on past empirical and theoretical studies (Kokkoris et al., 1999; Barabás et al., 2016; Gellner \& McCann, 2016). The weak competition strength plays a critical role in maintaining the population oscillation (McCann et al., 1998). Another point to note is that diversity in species interactions strength affects the stability and composition of the community and this agrees with other theoretical results (Landi et al., 2018; Karakoç et al., 2020).

From the dynamical systems viewpoints, our bifurcation analysis results emphasise the importance of numerical continuation studies in comprehending the overall dynamics of the complex ecological system and the stability properties of different attractors. The bifurcation results show the dynamics that occur in the system and the threshold values at which they occur. It further illustrates the presence of transcritical bifurcations in the 
ODE and PDE systems under consideration, as we vary competitive strength; the direct effects of this bifurcation can be seen in the species composition (presence-absence) as the magnitude of competitive strength changes, due to the exchange of stability between distinct steady states (Mohd, 2016). Other fascinating dynamical behaviours such as multi-species coexistence, stable and unstable limit cycles and aperiodic oscillations also emerge owing to the occurrences of Hopf bifurcations, limit point bifurcations of cycles and period-doubling bifurcations. In general, the presence of Hopf bifurcations gives birth to sustained oscillations that are uniform in space and periodic in time (Upadhyay et al., 2015; Upadhyay \& Roy, 2016; Moustafa et al., 2020). The presence of period-doubling bifurcation may lead to the possibility of chaotic dynamics in some ecological systems (Ladeira \& de Oliveira, 2019; Nath \& Das, 2020).

As a conclusion, our results demonstrate the crucial roles of competition and dispersal play in multiple interactions type models on the stability and coexistence of complex ecological systems. We show that dispersal has (de-)stabilising effects on the multi-species systems and that the interplay between dispersal and several biotic factors have significant consequences on the community dynamics. In this paper, we have made some simplification by assuming a symmetric dispersal strength $\left(D_{X}=D_{W}=D_{Y}=D_{Z}=\right.$ 0.005 ) in multiple interactions type model; in reality, not all species disperse with the same dispersal strength and some species are more mobile (or immobile) than the others. As demonstrated by some previous theoretical studies (Zhou, 2016; He \& Ni, 2013), the asymmetrical dispersal strength among species is another vital force that can shape multispecies community dynamics. For future work, we will consider this open problem and examine how the unequal dispersal strategies can determine the survival of species in this multiple interactions type system.

\section{ACKNOWLEDGEMENT}

This research is supported by the Universiti Sains Malaysia (USM) Fundamental Research Grant Scheme (FRGS) No. 203/PMATHS/6711645. The second author also wants to thank Ministry of Higher Education Malaysia for the financial support under the MOHE Postdoctoral Training Award that gives him the opportunity to do research in Universiti Kebangsaan Malaysia.

\section{REFERENCES}

Abbott, K. C. (2011). A dispersal-induced paradox: Synchrony and stability in stochastic metapopulations. Ecology Letters, 14(11), 1158-1169. https://doi.org/10.1111/j.1461-0248.2011.01670.x

Aliyu, M. B., \& Mohd, M. H. (2021). Combined impacts of predation, mutualism and dispersal on the dynamics of a four-species ecological system. Pertanika Journal of Science \& Technology, 29(1), 239-244. https:// doi.org/10.47836/pjst.29.1.13 
Allesina, S., \& Tang, S. (2012). Stability criteria for complex ecosystems. Nature, 483(7388), 205-208. https:// doi.org/10.1038/nature10832

Amarasekare, P. (2016). Evolution of dispersal in a multi-trophic community context. Oikos, 125(4), 514-525. https://doi.org/10.1111/oik.02258

Anderson, K. E., \& Hayes, S. M. (2018). The effects of dispersal and river spatial structure on asynchrony in consumer-resource metacommunities. Freshwater biology, 63(1), 100-113. https://doi.org/10.1111/ fwb. 12998

Bach, L. A., Thomsen, R., Pertoldi, C., \& Loeschcke, V. (2006). Kin competition and the evolution of dispersal in an individual-based model. Ecological Modelling, 192(3-4), 658-666. https://doi.org/10.1016/j. ecolmodel.2005.07.026

Baek, H. (2018). Complex dynamics of a discrete-time predator-prey system with ivlev functional response. Mathematical Problems in Engineering, 2018, Article 8635937. https://doi.org/10.1155/2018/8635937

Barabás, G., D’Andrea, R., \& Stump, S. M. (2018). Chesson's coexistence theory. Ecological Monographs, 88(3), 277-303. https://doi.org/10.1002/ecm.1302

Barabás, G., J. Michalska-Smith, M., \& Allesina, S. (2016). The effect of intra-and interspecific competition on coexistence in multispecies communities. The American Naturalist, 188(1), E1-E12. https://doi. org/10.1086/686901

Barraquand, F., Louca, S., Abbott, K. C., Cobbold, C. A., Cordoleani, F., DeAngelis, D. L., \& Murray, D. L. (2017). Moving forward in circles: Challenges and opportunities in modelling population cycles. Ecology Letters, 20(8), 1074-1092. https://doi.org/10.1111/ele.12789

Bashkirtseva, I., Ryashko, L., \& Ryazanova, T. (2019). Stochastic variability and transitions to chaos in a hierarchical three-species population model. Chaos, Solitons \& Fractals, 119, 276-283. https:/doi. org/10.1016/j.chaos.2018.12.035

Bassett, A., Krause, A. L., \& Van Gorder, R. A. (2017). Continuous dispersal in a model of predatorprey-subsidy population dynamics. Ecological Modelling, 354, 115-122. https://doi.org/10.1016/j. ecolmodel.2017.02.017

Becks, L., Ellner, S. P., Jones, L. E., \& Hairston Jr, N. G. (2012). The functional genomics of an eco-evolutionary feedback loop: Linking gene expression, trait evolution, and community dynamics. Ecology Letters, 15(5), 492-501. https://doi.org/10.1111/j.1461- 0248.2012.01763.x

Bjørnstad, O. N. (2000). Cycles and synchrony: two historical 'experiments' and one experience. Journal of Animal Ecology, 69(5), 869-873. https://doi.org/10.1046/j.1365-2656.2000.00444.x

Briggs, C. J., \& Hoopes, M. F. (2004). Stabilizing effects in spatial parasitoid-host and predator-prey models: A review. Theoretical Population Biology, 65(3), 299-315. https://doi.org/10.1016/j.tpb.2003.11.001

Bullock, J. M., Kenward, R. E., \& Hails, R. S. (Eds.). (2002). Dispersal ecology: 42nd symposium of the British ecological society (Vol. 42). Cambridge University Press.

Carrara, F., Giometto, A., Seymour, M., Rinaldo, A., \& Altermatt, F. (2015). Inferring species interactions in ecological communities: A comparison of methods at different levels of complexity. Methods in Ecology and Evolution, 6(8), 895-906. https://doi.org/10.1111/2041-210X.12363 
Chaianunporn, T., \& Hovestadt, T. (2012). Evolution of dispersal in metacommunities of interacting species. Journal of Evolutionary Biology, 25(12), 2511-2525. https://doi.org/10.1111/j.1420-9101.2012.02620.x

Chaianunporn, T., \& Hovestadt, T. (2015). Evolutionary responses to climate change in parasitic systems. Global Change Biology, 21(8), 2905-2916. https://doi.org/10.1111/gcb.12944

Chesson, P. (2018). Updates on mechanisms of maintenance of species diversity. Journal of Ecology, 106(5), 1773-1794. https://doi.org/10.1111/1365-2745.13035

Chow, Y., Jang, S. R. J., \& Yeh, N. S. (2018). Dynamics of a population in two patches with dispersal. Journal of Difference Equations and Applications, 24(4), 543-563. https://doi.org/10.1080/10236198.2018.1428962

Crooks, K. R., \& Sanjayan, M. (Eds.). (2006). Connectivity conservation (Vol. 14). Cambridge University Press.

Crowley, P. H. (1981). Dispersal and the stability of predator-prey interactions. The American Naturalist, 118(5), 673-701. https://doi.org/10.1086/283861

Dey, S., \& Joshi, A. (2006). Stability via asynchrony in Drosophila metapopulations with low migration rates. Science, 312(5772), 434-436. https://doi.org/10.1126/science.1125317

Feyrer, F., Hobbs, J., Acuna, S., Mahardja, B., Grimaldo, L., Baerwald, M., Johnson, R. C., \& Teh, S. (2015). Metapopulation structure of a semi-anadromous fish in a dynamic environment. Canadian Journal of Fisheries and Aquatic Sciences, 72(5), 709-721. https://doi.org/10.1139/cjfas-2014-0433

Fussell, E. F., Krause, A. L., \& Van Gorder, R. A. (2019). Hybrid approach to modeling spatial dynamics of systems with generalist predators. Journal of Theoretical Biology, 462, 26-47. https://doi.org/10.1016/j. jtbi.2018.10.054

Fussmann, G. F., \& Gonzalez, A. (2013). Evolutionary rescue can maintain an oscillating community undergoing environmental change. Interface Focus, 3(6), Article 20130036. https://doi.org/10.1098/rsfs.2013.0036

Gandon, S. (1999). Kin competition, the cost of inbreeding and the evolution of dispersal. Journal of Theoretical Biology, 200(4), 345-364. https://doi.org/10.1006/jtbi.1999.0994

Gandon, S., \& Rousset, F. (1999). Evolution of stepping-stone dispersal rates. Proceedings of the Royal Society of London. Series B: Biological Sciences, 266(1437), 2507-2513. https://doi.org/10.1098/rspb.1999.0953

Gause, G. F. (1932). Experimental studies on the struggle for existence: I. Mixed population of two species of yeast. Journal of Experimental Biology, 9(4), 389-402.

Gellner, G., \& McCann, K. S. (2016). Consistent role of weak and strong interactions in high- and low-diversity trophic food webs. Nature Communications, 7(1), 1-7. https://doi.org/10.1038/ncomms11180

Goldwyn, E. E., \& Hastings, A. (2008). When can dispersal synchronize populations? Theoretical Population Biology, 73(3), 395-402. https://doi.org/10.1016/j.tpb.2007.11.012

Gotelli, N. J. (2008). A primer of ecology, Sunderland. Sinauer Associates.

Gouhier, T. C., Guichard, F., \& Gonzalez, A. (2010). Synchrony and stability of food webs in metacommunities. The American Naturalist, 175(2), E16-E34. https://doi.org/10.1086/649579

Green, D. M. (2009). Coevolution of dispersal in a parasitoid-host system. Population Ecology, 51(2), 253260. https://doi.org/10.1007/s10144-008-0131-3 
Grover, J. P., Hudziak, J., \& Grover, J. D. (1997). Resource competition (Vol. 19). Springer Science \& Business Media

Gupta, R. P., \& Yadav, D. K. (2020). Complex dynamical behavior of a three species prey-predator system with nonlinear harvesting. International Journal of Bifurcation and Chaos, 30(13), Article 2050195. https://doi.org/10.1142/S0218127420501953

Gyllenberg, M., Jiang, J., Niu, L., \& Yan, P. (2019). On the dynamics of multi-species Ricker models admitting a carrying simplex. Journal of Difference Equations and Applications, 25(11), 1489-1530. https://doi.or g/10.1080/10236198.2019.1663182

Hanski, I. (1998). Metapopulation dynamics. Nature, 396(6706), 41-49. https://doi.org/10.1038/23876

Hardin, G. (1960). The competitive exclusion principle. Science, 131(3409), 1292-1297.

He, X., \& Ni, W. M. (2013). The effects of diffusion and spatial variation in Lotka-Volterra competitiondiffusion system I: Heterogeneity vs. homogeneity. Journal of Differential Equations, 254(2), 528-546. https://doi.org/10.1016/j.jde.2012.08.032

Holyoak, M. (2000). Effects of nutrient enrichment on predator-prey metapopulation dynamics. Journal of Animal Ecology, 69(6), 985-997. https://doi.org/10.1111/j.1365-2656.2000.00453.x

Hovestadt, T., Kubisch, A., \& Poethke, H. J. (2010). Information processing in models for densitydependent emigration: a comparison. Ecological Modelling, 221(3), 405-410. https://doi.org/10.1016/j. ecolmodel.2009.11.005

Hudson, P. J., \& Cattadori, I. (1999). The Moran effect: A cause of population synchrony. Trends in Ecology and Evolution, 14(1), 1-2. https://doi.org/10.1016/S0169-5347 (98)

Hutchinson, G. E. (1961). The paradox of the plankton. The American Naturalist, 95(882), 137-145. https:// doi.org/10.1086/282171

Kakishima, S., Morita, S., Yoshida, K., Ishida, A., Hayashi, S., Asami, T., Ito, H., Miller III, D. G., Uehara, T., Mori, S., \& Hasegawa, E. (2015). The contribution of seed dispersers to tree species diversity in tropical rainforests. Royal Society Open Science, 2(10), Article 150330. https://doi.org/10.1098/rsos.150330

Karakoç, C., Clark, A. T., \& Chatzinotas, A. (2020). Diversity and coexistence are influenced by time-dependent species interactions in a predator-prey system. Ecology Letters, 23(6), 983-993. https://doi.org/10.1111/ ele. 13500

Kendall, B. E., Bjørnstad, O. N., Bascompte, J., Keitt, T. H., \& Fagan, W. F. (2000). Dispersal, environmental correlation, and spatial synchrony in population dynamics. The American Naturalist, 155(5), 628-636. https://doi.org/10.1086/303350

Kindlmann, P., \& Burel, F. (2008). Connectivity measures: A review. Landscape ecology, 23(8), 879-890. https://doi.org/10.1007/s10980-008-9245-4

Koch, H., Frickel, J., Valiadi, M., \& Becks, L. (2014). Why rapid, adaptive evolution matters for community dynamics. Frontiers in Ecology and Evolution, 2, Article 17. https://doi.org/10.3389/fevo.2014.00017

Kokkoris, G. D., Troumbis, A. Y., \& Lawton, J. H. (1999). Patterns of species interaction strength in assembled theoretical competition communities. Ecology Letters, 2(2), 70-74. https://doi.org/10.1046/j.14610248.1999.22058.x 
Kondoh, M. (2008). Building trophic modules into a persistent food web. Proceedings of the National Academy of Sciences, 105(43), 16631-16635. https://doi.org/10.1073/pnas.0805870105

Kondoh, M., \& Mougi, A. (2015). Interaction-type diversity hypothesis and interaction strength: The condition for the positive complexity-stability effect to arise. Population Ecology, 57(1), 21-27. https://doi. org/10.1007/s10144-014-0475-9

Kool, J. T., Moilanen, A., \& Treml, E. A. (2013). Population connectivity: Recent advances and new perspectives. Landscape Ecology, 28(2), 165-185. https://doi.org/10.1007/s10980-012-9819-z

Kouvaris, N., Kugiumtzis, D., \& Provata, A. (2011). Species mobility induces synchronization in chaotic population dynamics. Physical Review E, 84(3), Article 036211.

Ladeira, D. G., \& de Oliveira, M. M. (2019). Chaotic coexistence in a resource-consumer model. Journal of Biological Systems, 27(02), 167-184. https://doi.org/10.1142/S0218339019500086

Lampert, A., \& Hastings, A. (2016). Stability and distribution of predator-prey systems: Local and regional mechanisms and patterns. Ecology letters, 19(3), 279-288. https://doi.org/10.1111/ele.12565

Landi, P., Minoarivelo, H. O., Brännström, Å., Hui, C., \& Dieckmann, U. (2018). Complexity and stability of ecological networks: A review of the theory. Population Ecology, 60(4), 319-345. https://doi.org/10.1007/ s10144-018-0628-3

Lee, A. M., Sæther, B. E., \& Engen, S. (2020). Spatial covariation of competing species in a fluctuating environment. Ecology, 101(1), Article e02901. https://doi.org/10.1002/ecy.2901

Leibold, M. A., \& Chase, J. M. (2017). Metacommunity ecology (Vol. 59). Princeton University Press.

Liu, X., \& Huang, Q. (2018). The dynamics of a harvested predator-prey system with Holling type IV functional response. Biosystems, 169, 26-39. https://doi.org/10.1016/j.biosystems.2018.05.005

Loreau, M. (2010). Linking biodiversity and ecosystems: Towards a unifying ecological theory. Philosophical Transactions of the Royal Society B: Biological Sciences, 365(1537), 49-60. https://doi.org/10.1098/ rstb.2009.0155

McCann, K., Hastings, A., \& Huxel, G. R. (1998). Weak trophic interactions and the balance of nature. Nature, 395(6704), 794-798. https://doi.org/10.1038/27427

Mitani, N., \& Mougi, A. (2017). Population cycles emerging through multiple interaction types. Royal Society Open Science, 4(9), Article 170536. https://doi.org/10.1098/rsos.170536

Mittelbach, G. G., \& McGill, B. J. (2019). Community ecology. Oxford University Press.

Mohd, M. H. (2018). Numerical bifurcation and stability analyses of partial differential equations with applications to competitive system in ecology. In SEAMS School on Dynamical Systems and Bifurcation Analysis (pp. 117-132). Springer. https://doi.org/10.1007/978-981-32-9832-3_7

Mohd, M. H. (2019). Diversity in interaction strength promotes rich dynamical behaviours in a three-species ecological system. Applied Mathematics and Computation, 353, 243-253. https://doi.org/10.1016/j. amc.2019.02.007

Mohd, M. H. B. (2016). Modelling the presence-absence of multiple species (Doctoral dissertation). University of Canterbury. http://dx.doi.org/10.26021/1670 
Mohd, M. H., \& Noorani, M. S. M. (2020). Local dispersal, trophic interactions and handling times mediate contrasting effects in prey-predator dynamics. Chaos, Solitons \& Fractals, 142, Article 110497. https:// doi.org/10.1016/j.chaos.2020.110497

Mohd, M. H., Murray, R., Plank, M. J., \& Godsoe, W. (2016). Effects of dispersal and stochasticity on the presence-absence of multiple species. Ecological Modelling, 342, 49-59. https://doi.org/10.1016/j. ecolmodel.2016.09.026

Mohd, M. H., Murray, R., Plank, M. J., \& Godsoe, W. (2017). Effects of biotic interactions and dispersal on the presence-absence of multiple species. Chaos, Solitons \& Fractals, 99, 185-194. https://doi.org/10.1016/j. chaos.2017.04.012

Mohd, M. H., Murray, R., Plank, M. J., \& Godsoe, W. (2018). Effects of different dispersal patterns on the presence-absence of multiple species. Communications in Nonlinear Science and Numerical Simulation, 56, 115-130. https://doi.org/10.1016/j.cnsns.2017.07.029

Mondor, E. B., Rosenheim, J. A., \& Addicott, J. F. (2005). Predator-induced transgenerational phenotypic plasticity in the cotton aphid. Oecologia, 142(1), 104-108. https://doi.org/10.1007/s00442-004-1710-4

Mougi, A. (2012). Unusual predator-prey dynamics under reciprocal phenotypic plasticity. Journal of theoretical biology, 305, 96-102. https://doi.org/10.1016/j.jtbi.2012.04.012

Mougi, A. (2016). Stability of an adaptive hybrid community. Scientific reports, 6, Article 28181. https://oi. org/10.1038/srep28181

Mougi, A., \& Kondoh, M. (2012). Diversity of interaction types and ecological community stability. Science, 337(6092), 349-351. https://doi.org/10.1126/science.1220529

Mougi, A., \& Kondoh, M. (2014). Adaptation in a hybrid world with multiple interaction types: A new mechanism for species coexistence. Ecological Research, 29(2), 113-119. https://doi.org/10.1007/ s11284-013-1111-4

Moustafa, M., Mohd, M. H., Ismail, A. I., \& Abdullah, F. A. (2020). Dynamical analysis of a fractional-order eco-epidemiological model with disease in prey population. Advances in Difference Equations, 2020(1), Article 48. https://doi.org/10.1186/s13662-020-2522-5

Namba, T., Takeuchi, Y., \& Banerjee, M. (2018). Stabilizing effect of intra-specific competition on prey-predator dynamics with intraguild predation. Mathematical Modelling of Natural Phenomena, 13(3), Article 29. https://doi.org/10.1051/mmnp/2018033

Nath, B., \& Das, K. P. (2020). Harvesting in tri-trophic food chain stabilises the chaotic dynamics-conclusion drawn from Hastings and Powell model. International Journal of Dynamical Systems and Differential Equations, 10(2), 95-115. https://doi.org/10.1504/IJDSDE.2020.106025

Omaiye, O. J., \& Mohd, M. H. (2018). Computational dynamical systems using XPPAUT. In SEAMS School on Dynamical Systems and Bifurcation Analysis (pp. 175-203). Springer. https://doi.org/10.1007/978981-32-9832-3_10

Perrin, N., \& Goudet, J. (2001). Inbreeding, kinship, and the evolution of natal dispersal. Dispersal, 123-142. 
Poethke, H. J., \& Hovestadt, T. (2002). Evolution of density-and patch-size-dependent dispersal rates. Proceedings of the Royal Society of London. Series B: Biological Sciences, 269(1491), 637-645. https:// doi.org/10.1098/rspb.2001.1936

Poethke, H. J., Hovestadt, T., \& Mitesser, O. (2003). Local extinction and the evolution of dispersal rates: Causes and correlations. The American Naturalist, 161(4), 631-640. https://doi.org/10.1086/368224

Poethke, H. J., Pfenning, B., \& Hovestadt, T. (2007). The relative contribution of individual and kin selection to the evolution of density-dependent dispersal rates. Evolutionary Ecology Research, 9(1), 41-50.

Poethke, H. J., Weisser, W. W., \& Hovestadt, T. (2010). Predator-induced dispersal and the evolution of conditional dispersal in correlated environments. The American Naturalist, 175(5), 577-586. https:// doi.org/10.1086/651595

Rozhnova, G., Metcalf, C. J. E., \& Grenfell, B. T. (2013). Characterizing the dynamics of rubella relative to measles: the role of stochasticity. Journal of The Royal Society Interface, 10(88), Article 20130643. https://doi.org/10.1098/rsif.2013.0643

Selvam, A. G. M., \& Dhineshbabu, R. (2020). Bifurcation and chaos in a discrete fractional order prey-predator system involving infection in prey. In Mathematical Models of Infectious Diseases and Social Issues (pp. 95-119). IGI Global.

Shabunin, A. V., Efimov, A., Tsekouras, G. A., \& Provata, A. (2005). Scaling, cluster dynamics and complex oscillations in a multispecies Lattice Lotka-Volterra Model. Physica A: Statistical Mechanics and its Applications, 347, 117-136. https://doi.org/10.1016/j.physa.2004.09.021

Shabunin, A., \& Provata, A. (2013). Lattice limit cycle dynamics: Influence of long-distance reactive and diffusive mixing. The European Physical Journal Special Topics, 222(10), 2547-2557. https://doi. org/10.1140/epjst/e2013-02036-5

Steiner, C. F., Stockwell, R. D., Kalaimani, V., \& Aqel, Z. (2013). Population synchrony and stability in environmentally forced metacommunities. Oikos, 122(8), 1195-1206. https://doi.org/10.1111/j.16000706.2012.20936.x

Travis, J. M. (2001). The color of noise and the evolution of dispersal. Ecological Research, 16(1), 157-163. https://doi.org/10.1046/j.1440-1703.2001.00381.x

Tubay, J. M., Ito, H., Uehara, T., Kakishima, S., Morita, S., Togashi, T., Tainaka, K., Niraula, M. P., Casareto, B. E., Suzuki, Y. \& Yoshimura, J. (2013). The paradox of enrichment in phytoplankton by induced competitive interactions. Scientific Reports, 3(1), 1-8. https://doi.org/10.1038/srep02835

Turchin, P. (2003). Complex population dynamics: A theoretical/empirical synthesis (Vol. 35). Princeton University Press.

Upadhyay, R. K., \& Roy, P. (2016). Disease spread and its effect on population dynamics in heterogeneous environment. International Journal of Bifurcation and Chaos, 26(01), Article 1650004. https://doi. org/10.1142/S0218127416500048

Upadhyay, R. K., Roy, P., \& Datta, J. (2015). Complex dynamics of ecological systems under nonlinear harvesting: Hopf bifurcation and Turing instability. Nonlinear Dynamics, 79(4), 2251-2270. https://doi. org/10.1007/s11071-014-1808-0 
Vasseur, D. A., \& Fox, J. W. (2009). Phase-locking and environmental fluctuations generate synchrony in a predator-prey community. Nature, 460(7258), 1007-1010. https://doi.org/10.1038/nature08208

Vellend, M. (2020). The theory of ecological communities (MPB-57). Princeton University Press.

Verma, T., \& Gupta, A. K. (2020). Mean-field dispersal induced synchrony and stability in an epidemic model under patchy environment. Physica A: Statistical Mechanics and its Applications, 541, Article 123300. https://doi.org/10.1016/j.physa.2019.123300

Vogwill, T., Fenton, A., \& Brockhurst, M. A. (2009). Dispersal and natural enemies interact to drive spatial synchrony and decrease stability in patchy populations. Ecology Letters, 12(11), 1194-1200. https://doi. org/10.1111/j.1461-0248.2009.01374.x

Wei, Z., Xia, Y., \& Zhang, T. (2020). Stability and bifurcation analysis of an amensalism model with weak Allee effect. Qualitative Theory of Dynamical Systems, 19(1), Article 23. https://doi.org/10.1007/s12346020-00341-0

Williams, P. D., \& Hastings, A. (2013). Stochastic dispersal and population persistence in marine organisms. The American Naturalist, 182(2), 271-282.

Yaari, G., Ben-Zion, Y., Shnerb, N. M., \& Vasseur, D. A. (2012). Consistent scaling of persistence time in metapopulations. Ecology, 93(5), 1214-1227. https://doi.org/10.1890/11-1077.1

Zhou, P. (2016). On a Lotka-Volterra competition system: diffusion vs advection. Calculus of Variations and Partial Differential Equations, 55(6), 137. https://doi.org/10.1007/s00526-016-1082-8 
